\title{
Influence of Participatory Decision Making on Job Satisfaction: The Moderating Effect of Staff Experience
}

\author{
Abdulmajid M. A. Aldaba \\ Kulliyyah of Education, \\ International Islamic University Malaysia, \\ Kuala Lumpur, Malaysia \\ drmajid@iium.edu.my \\ Said R. A. Alshuhumi \\ Ministry of Education, \\ Sultanate of Oman, Oman \\ said.alshahome@moe.om
}

\author{
Hairuddin Mohd Ali \\ Kulliyyah of Education, \\ International Islamic University Malaysia, \\ Kuala Lumpur, Malaysia \\ hairuddin@iium.edu.my \\ Jafar Paramboor \\ Kulliyyah of Education, \\ International Islamic University Malaysia, \\ Kuala Lumpur, Malaysia \\ jafarpoovathani@gmail.com
}

\begin{abstract}
The relationship between participatory decision-making (PDM) and job satisfaction (JS) has attracted the attention of researchers not only in the field of business industries but also education sector. However, the issue has not been given noteworthy priority in educational administration research let alone in Islamic tertiary institution context. Thus, the purpose of this study is threefold: 1) to validate the psychometric properties of administrative staff's PDM and JS constructs, 2) to examine the degree of influence of administrative staff's PDM on their JS, and 3) test the moderating role of staff's working experience on the influence of PDM on JS. Using a quantitative survey approach, data were collected from 255 administrative staff working in different faculties, divisions, and centers of International Islamic University Malaysia (IIUM). The study employed co-variance-based SEM by using AMOS version 24 in order to achieve the objectives. First, Confirmatory Factor Analysis (CFA) was employed to test the psychometric properties (such as convergent validity, divergent validity, and reliability) for both PDM and JS. Second, a Full-Fledged SEM was conducted to test the influence of PDM on JS. Finally, to examine the moderating effect of the staff working experience in the relationship between PDM and JST, a multi-group analysis (MGA) was applied. The results confirmed that the multidimensional hypothesized model of PDM and JS were empirically valid and reliable. The results also revealed a statistically significant impact for PDM on JS. Besides, the working experience was found to have a moderating role in the effect of PDM on JS. The study suggests that administrative staff involvement in decision making process is highly required as it increases their job satisfaction.
\end{abstract}

Keywords: Participatory decision making, job satisfaction, administrative staff, structural equation modelling 


\section{INTRODUCTION}

Previous studies have established that job satisfaction, performance, and manager and employee relationship are sine qua non to the work environment (AbuAlRub et al., 2016; Badrianto \& Ekhsan, 2020; Chandra, 2016; Hayes, et al., 2015; Wang \& Brower, 2019). In reference to this, Hertzberg et al. (1957) asserted that managers with adequate and applicable management skills and practices - such as giving employees the freedom to carry out their functions, inspiring them with required skills and training, and offering opportunities for promotion and career development - would have positive effects on employee success. In other words, employees who actively engage in the decision-making process by interacting with all members in an organization hierarchy will be more committed and motivated to perform compared to those operating under the iron hand in the velvet glove approach.

A successful management strategy is one that creates an encouraging working atmosphere and has workers actively involved in the decision-making process. Such a strategy is likely to produce six outcomes in the workplace, i.e., positive results, job satisfaction, greater efficiency, appreciation, self-actualization, and a sense of pride. As workers develop a sense of being part of the organization's policy making, they become increasingly integral to the context they are working in. Moorhead and Griffin (2004) maintained that allowing staff to take part in decisionmaking is a great way to ensure that they appreciate the association between their success and the remuneration they get from the organization at the end of the day. This view is similar to that emphasized by Devente et al. (2016) in a socioecological context. Devente and colleagues investigated how participatory approaches to the management of socioecological structures contributed to better informed and sustainable environmental decisions or policies, promoted their adoption and implementation, and thus more effectively achieved their environmental goals. In addition, they considered how a participatory approach benefited the participants in improving their learning and confidence, as well as in achieving their specified objectives.

Kuye and Sulaimon (2011) inquired whether giving workers the right to engage in decision-making and providing them with good remuneration and proper service conditions, like a better working environment, would have any effect on their job satisfaction. In response, Emmanuel and Damachi (2015) explained that the degree of employee satisfaction is defined by the needs and desires of each worker in an organization. Nevertheless, they find employee involvement in decision-making and the general climate of the supporting work environment as significant contributing factors of employee job satisfaction. In this regard, the present study's concern is to examine the participatory decision-making process and its specific effect on the job satisfaction of non-academic staff in an Islamic higher learning institution. 


\section{LITERATURE REVIEW}

\section{Participatory Decision Making (PDM)}

Participatory decision making (PDM) has been discussed considerably in the literature in different contexts such as management (Chizoba et al., 2019; De Vente et al., 2016), business (Oloo \& Orwar, 2016; Ugwu et al., 2019), communication (Xia et al., 2016), technology usage (Bilge et al., 2016), education (Hollyns, 2017; Konings et al., 2017), and welfare (Kennan et al., 2018). Interestingly, scholars have specifically defined the term PDM and elaborated what it means in multiple contexts. According to Noah (2008), PDM is a process whereby employees of an organization exercise the right to influence organizational decisions when the communication gap between the employees and the authority is properly bridged. Without significant variation in idea, Probst (2005) defined PDM as the extent to which employers in an organization permit their employees to engage in the process of decision making. In both definitions, the element of mutual engagement is emphasized.

Hence, participation as a substantial element in PDM, is the process in which every individual, notwithstanding their differential places in the hierarchy, takes part in an activity (Wagner, 1994). It is also defined as the involvement of every employee in an organization (Monge \& Miller, 1988). Furthermore, PDM is described as the process of exercising authority and disseminating information in a more balanced manner, with information flowing vertically from the employers to the managers and those working under them (Beardwell \& Claydon, 2007).

Based on the various definitions of participation given by previous researchers (Bhatti \& Nawab, 2011; Busck et al., 2010; Sofijanova \& Chatleska, 2013; Westhuizen, 2010;), it can be synthesized that participatory management is a line-management system in which problemsolving and decision-making knowledge flows between managers and their subordinates (Wagner, 1994). PDM in an organizational context is vital to a wide range of processes including planning, organizing, directing, coordinating, controlling, staffing, reporting, and budgeting while it functions as an identity of the organization (Hollyns, 2017).

As for worker engagement, participation of employees in decision making is also important. Depending on the prevailing socio-technology and political system of the company involved, employee decision-making can be exercised by members of the organization. It should be emphasized that decision-making can be a formal or informal cognitive mechanism as it includes the individual's mental and physical capacities, as well as his or her feelings (Luthans, 2005). On the other hand, Graham and Bennet (1998) believe that the decisionmaking process ensures that employees have access to appropriate information about the organization's overall health. Therefore, they should still be informed and included in all discussions by their representatives before any decision can be made. In other words, involvement includes participation in the decision-making process of all interested parties. Typically, the personal and community involvement in the decision-making process is generally accomplished by the following consultative and democratic techniques: 
a) Involved engagement strategies - These demand that each employee engage in all facets of their job. This is in appreciation of the fact that individuals' decision-making processes have an effect on administrative functions.

b) Consultative strategies - These are methods that enable managers to enlist the help of employees in making decisions, while the final analysis is made by the management retaining his or her power of discretion in the decisionmaking process.

c) Democratic decision-making - This is a collective or a group participation as opposed to individual participation. It guarantees that the majority view or consensus is the only valid way to make decisions (Luthans, 2005).

In the education sector, the issue of urban poverty and schooling in Malaysia is impacting students in major cities. Urban schools located in large low-income population areas were reported to have an approximately $87 \%$ attendance level (Che Mat, 2017). The relatively high level of absenteeism has negatively affected the academic achievement of urban poor students. In addition, Hong (2017) found that most teachers in urban schools perceived that poor urban students' underachievement was related to external factors that included social class, family background and their general living conditions, such as the lack of parental support, technology, funds, and ability, in addition to economic struggles of the home and the school. All these factors were perceived to be responsible for the decline of students' aspirations in schools and influence their efforts, motivation, and academic performance.

\section{Job Satisfaction}

In a company, employees' success is measured by their satisfaction in the working context. As for the worker, job satisfaction is intended to gain job security and motivate his or her performance. This makes the worker committed up to the expected level. It rejuvenates the interests of workers, decreases absenteeism, and diminishes employee-turn-over. Employment satisfaction ensures workers' participation and a peaceful workforce for the employer. This saves organizational expenditure on new recruitments and training and development activities. Generally, most established companies consider the factors of organizational health, morale, and job satisfaction of workers as important as their efficiency (Luthans, 2005).

Spector (1997) noted that the depth and degree to which workers like or hate their work is measured by job satisfaction. In his view, job satisfaction is a factor that emphasizes workers' positive orientation towards their occupational tasks. Spector believed that making employees happy and maintaining a satisfactory work atmosphere for them are, however, the most challenging tasks. This gets even more tedious when it comes to those employees with comparatively more experience and better qualifications. Since job satisfaction is defined as the positive perception and attitude of employees towards their job (Armstrong, 2006), their degree of optimistic attitudes towards their job will be positive as well to some degree. Pursuant to that, the happier they are, the more optimistic they will be in their job attitude. In an opposite scenario, a negative attitude towards work is a sign of disappointment with one's employment. 
Simultaneously, morale is considered to represent happiness (Armstrong, 2006). Morale, according to Guion (1958), is the amount of enthusiasm required to make an individual employee happy with their work and their perception of what job satisfaction entails. Employee satisfaction, according to Lawler (1971), is a positive perception of how employees perceive their jobs. In other words, satisfaction is an integral part of motivation. As cited by Munidi (2011) and Gumato (2003), satisfaction is described as how employees maintain a positive attitude toward their jobs. They also emphasize that high levels of satisfaction result from the relationship between what the employees desire (in terms of compensation) and what they actually receive. Employees who are well-cared for and inspired are happier with their work, more loyal and cooperative, and eventually are profitable to the business.

In contrast, dissatisfied workers tend to feel demoralized, resulting in low attendance, higher absenteeism, low productivity, easy strike and picketing, which eventually lead them to leave the company. The moment workers begin to realize the benefits they are accruing from their efficiency and success, their performance, work satisfaction, and productivity increase to a great extent. Looking from this perspective, job satisfaction creates a conducive working environment for employees, making them happy and comfortable with their status and position. Thus, it is clear that having happy employees will result in increased organizational productivity.

Studies on the involvement of workers in the decision-making process and job satisfaction are phenomenal and have received particular attention from Western scholars. In general, most of them indicated that the involvement of workers in organizational decision-making does produce beneficial results. Moreover, workers who engage in the decision-making process showed higher levels of motivation and efficiency (Abdulai \& Shafiwu, 2014). In fact, all organizational theorists, including Agyris, MCGregory, Herzberg, Likert, and Ouchie, have documented organizational effectiveness and high staff morale when employees are allowed to engage actively in decision making (Hollyns, 2017). Herzberge's motivation theory even establishes that workers are not necessarily just motivated by extrinsic factors such as salary and bonus, but also by intrinsic factors that include achievement, sense of belonging, and recognition. Therefore, going by this premise, it is hypothesized that PDM is a significant contributor of job satisfaction.

A study conducted in an Eastern context (i.e., Xia et al., 2016) explored the impact of PDM on job satisfaction among the employees of a manufacturing company. In this study, PDM was established as a factor that always predicted communication openness. Thus, communication openness was treated as a mediator variable that would also influence job satisfaction. In this sense, the researchers highlighted that the relationship between PDM and employee job satisfaction is comparatively more complex than the usually perceived direct and positive correlation.

In similar circumstances, job satisfaction has also been treated as a mediating construct between HR practices and employee job performance. Studies by Khan et al. (2018) and Mira et al. (2019) found that although the latter did not exhibit any significant mediating impact, the hypotheses were all supported with regard to the former. Nevertheless, they identified that job satisfaction is a predictor of employee performance with a direct positive effect. 
Trivellas and Santouridis (2014) discovered that job satisfaction positively mediated the association between administrative quality and effective commitment. They also highlighted that although most of the studies on job satisfaction have been done in profit-oriented organizations (e.g., Pang \& Lu, 2018), a growing number of studies in the area are looking into the higher education sector as well (Bayram \& Dinç, 2015; Fassoulis \& Alexopoulos, 2015; Khan et al., 2018), with a keen interest in and concern for quality management. The primary reason for this growing interest, as the authors observed, is the higher education sector's paradigm shift towards becoming a labour-intensive industry. As a result of this shift and growing awareness, they have begun giving due consideration to the human factor in organizational management and leadership and the aspects influencing its effectiveness.

\section{The Enduring Issues}

There is always a big question mark if the results of the related studies performed in the Western context can be generalized to Muslim institutions with an Islamic culture, in general, and to the Malaysian context, in particular. Moreover, while several studies have focused on the correlation between participatory decision-making and work satisfaction for academic workers, only a few concentrated on participatory decision-making among non-academic staff. Due to the paucity of studies on participatory decision-making at Islamic tertiary institutions, Opatokun and Hasim (2013) recommended the conduct of a comprehensive research involving non-academic staff. Although extensive research has examined the relationship between participatory decision-making and work satisfaction among academic staff (Farinde-Wu \& Fitchett, 2016), few studies exploring the same association have involved non-academic administrative staff as the sample. To fill this gap, it is imperative to carry out a study on the work satisfaction resulting from PDM among administrative staff.

\section{Conceptual Framework}

Luthan's (2005) definition of Participative Decision Making (PDM) as a multidimensional concept served as the study's theoretical underpinning. In light of this idea, participatory decision-making can include multidimensional elements. PDM was described in the context of the current study as what administrative staff believe they know about the following three important dimensions: (i) Involved participatory decision making, (ii) Democratic participatory decision making, and (iii) Consultative participatory decision making. Similarly, job satisfaction (JS) was described as what administrative employees believe they are experiencing in three key dimensions: (i) Job satisfaction with the general work, (ii) promotion, (iii) and feedback. Given the empirical evidence supporting the impact of PDM on job satisfaction, it was hypothesized that the measure of PDM in this study would influence the JS of the administrative staff. The key concepts and the relationships among the PDM constructs are indicated in Figure 1. 


\section{Figure 1}

Conceptual Framework Illustrating the Influence of PDM on JS

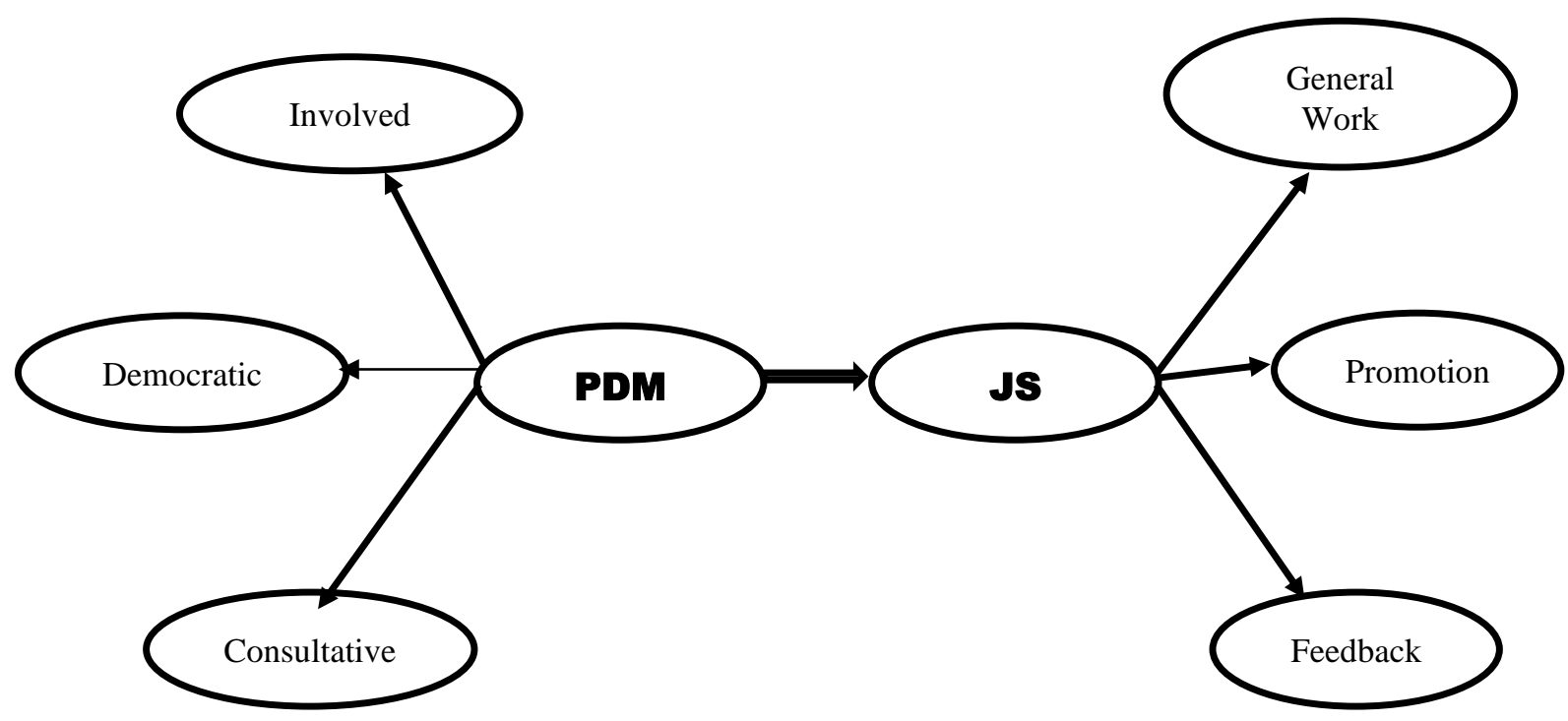

\section{Objectives and Research Questions}

The main aim of the study was to examine the influence of PDM on JS. The study also sought to examine the underlying factors of PDM and JS. The specific objectives of this study were as follows:

i) To validate the psychometric properties of administrative staff's PDM and JS constructs in terms of their reliability, convergent validity, and discriminant validity.

ii) To examine the degree of influence of administrative staff's PDM on their JS.

iii) To test the moderating role of staff's working experience on the influence of PDM on JS.

The research questions were as follows:

i) Are the study's PDM and JS constructs valid and reliable?

ii) To what degree does administrative staff's PDM influence their JS?

iii) Does staff's working experience moderate the influence of PDM on JS?

And the corresponding research hypotheses were:

H1: The multidimensional measure of PDM is valid and reliable.

$\mathrm{H} 2$ : The multidimensional measure of JS is valid and reliable.

H3: Administrative staff's PDM directly and significantly influences their JS.

H4: Administrative staffs' working experience moderates the influence of PDM on JS. 


\section{METHODOLOGY}

\section{Sampling}

Two hundred fifty-five ( $\mathrm{N}=255$ ) administrative staff from different Kulliyyahs, divisions and centers of the International Islamic University Malaysia (IIUM) took part in this study. Most of the respondents were female $(n=188,73.7 \%)$. They were categorized into five groups in terms of work experience. Those with one (1) to three (3) years of working experience were the largest group ( $\mathrm{n}=70,27.5 \%)$, followed by administrative staff who had between four (4) and nine (9) years $(23.5 \%)$ and those with 20 years and more $(23.1 \%)$ of work experience. However, the smallest groups were those who had between 10 to 14 years of work experience $(n=27,10.6 \%)$ and those who had between 15 and 19 years $(n=39,15.3 \%)$. The sample size was deemed adequate for the application of multivariate analysis, particularly structural equation modelling (SEM) to address the research objectives (Kline, 2015) and research questions.

\section{Table 1}

Sample Breakdown by Gender and Work Experience $(\mathrm{N}=255)$

\begin{tabular}{lccc}
\hline Variable & Category & Frequency & Percentage \\
\hline Gender & Male & 67 & 26.3 \\
& Female & 188 & 73.7 \\
\hline \multirow{4}{*}{ Work Experience } & $1-3$ years & 70 & 27.5 \\
& 4-9 years & 60 & 23.5 \\
& $10-14$ years & 39 & 15.3 \\
& $15-19$ years & 27 & 10.6 \\
& 20 years and more & 59 & 23.1 \\
\hline
\end{tabular}

\section{Measures of PDM and JS}

The study used a 30-item questionnaire where 14 of the items measured staff's PDM, while the remaining 16 items measured their JS. The items were primarily drawn from an extensive review of literature on PDM and JS and was partly adopted and adapted from Muindi (2011). The items were empirically tested a few times prior to being used in the present study. All 14 items measured PDM collectively via the three factors representing the construct. The respondents were asked to respond to the measures based on a five-point Likert scale, consisting of Never, Occasionally, Often, Mostly, and Always. Meanwhile, the staff's JS was represented by sixteen (16) items with three hypothesized dimensions, i.e., staff satisfaction with general work, staff satisfaction with promotion, and staff job satisfaction with feedback. These survey questions were also rated on a five-point Likert scale, i.e., Very Dissatisfied, Dissatisfied, Neutral, Satisfied, and Very Satisfied. 


\section{Data Analysis}

This study used a covariance-based SEM on AMOS version 24 in order to achieve the research objectives. First, confirmatory factor analysis (CFA) was employed to test the psychometric properties (i.e., the convergent validity, divergent validity, and reliability of the measures) for both PDM and JS. Second, a full-fledged SEM was conducted to test the influence of PDM on JS. Finally, a multigroup analysis (MGA) was applied to examine the moderating effect of staff working experience on the relationship between PDM and JS.

\section{RESULTS}

Based on the research objectives, research questions and the corresponding hypotheses, this section presents the results of the study.

\section{CFA Results for PDM}

In determining the convergent validity, divergent validity, and composite reliability of PDM, CFA was run on the data drawn from the sample $(n=255)$. The initial measurement model exhibited unsatisfactory fit indices due to the presence of a few items with low loadings. To fix the model fit, the analysis followed the modification indices which suggested the deletion of five problematic items (i.e., PDM4, PDM5, PDM6, PDM 10, and PDM 15). Therefore, the outcomes of the estimated measurement model indicated that the three-factor structure of PDM was adequate to represent the data. The goodness-of-fit indices of the model were reasonable, with the Relative Normed Chi-square $=2.446$; RMSEA $=.075 ; \mathrm{CFI}=.968$; and TLI=.953.

\section{Figure 2}

The Revised CFA Model Confirming a Three-Factor Structure of PDM

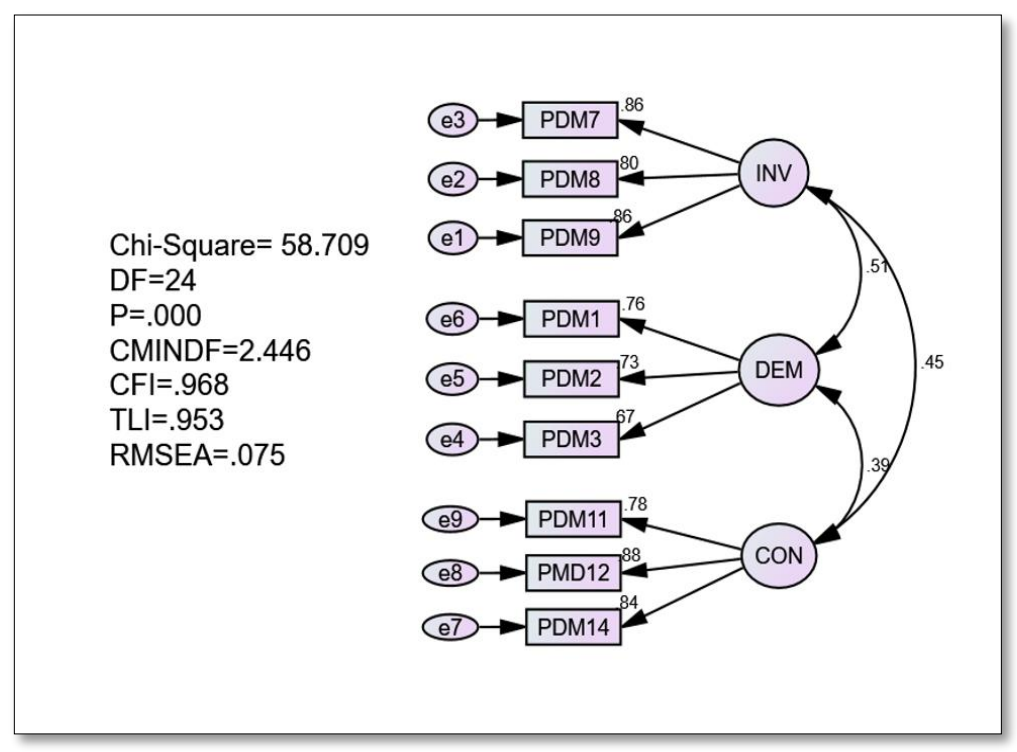

The psychometric properties of the PDM measurement model were determined through its convergent validity, discriminant validity, and composite reliability. As exhibited in Figure 2, 
the item loadings ranged from 0.67 to 0.88 and were acceptable as they were more than 0.50 . Therefore, the presence of item loadings above 0.50 along with an average variance extracted (AVE) value of above 0.50 was satisfactory evidence of the model's convergent validity (Hair et al., 2014). Table 2 below also shows that the average variance extracted (AVE) values are more than the squared correlations for each set of constructs. Hence, according to Fornell and Larcker (1981), this is an acceptable evidence of discriminant validity. Finally, as exhibited in Table 2, the composite reliability (CR) values are all above 0.70 , and thus presented good evidence of composite reliability (Hair, et al., 2014). The results above fulfilled the first objective of the study.

\section{Table 2}

Convergent Validity, Discriminant Validity and Reliability of the PDM Constructs

\begin{tabular}{cccccc}
\hline Subconstruct & $\mathbf{1}$ & $\mathbf{2}$ & $\mathbf{3}$ & AVE & CR \\
\hline Involved & $\mathbf{0 . 7 0 6}$ & 0.202 & 0.151 & 0.706 & 0.878 \\
Democratic & 0.450 & $\mathbf{0 . 5 2 0}$ & 0.260 & 0.520 & 0.764 \\
Consultative & 0.389 & 0.510 & $\mathbf{0 . 6 9 6}$ & 0.696 & 0.872 \\
\hline
\end{tabular}

Note. (i) Shown diagonally are the average variance extracted (AVEs) for each subconstruct; below the diagonal is the correlation matrix; above the diagonal is the shared variance matrix; (ii) All AVEs were larger than the shared variances.

\section{CFA Results for JS}

In order to verify the convergent validity, divergent validity, and composite reliability of JS, CFA was run on the data drawn from the sample $(\mathrm{N}=255)$. The initial model exhibited unsatisfactory fit indices due to the presence of some items with low loading values. Accordingly, five items (i.e., JS4, JS5, JS10, JS11 and JS15) were deleted following the suggestions of the modification indices. Thus, the outcomes of the estimated measurement model indicated that the three-factor structure of participatory decision making was adequate to represent the data. The model's goodness-of-fit was reasonable, with the Relative Normed Chi-square $=2.313 ;$ RMSEA $=.072 ; \mathrm{CFI}=.963 ;$ and TLI $=.941$.

\section{Figure 3}

The Revised CFA Model Confirming a Three-Factor Structure of JS

Chi-Square $=94.817$

$\mathrm{DF}=41$

$\mathrm{P}=.000$

CMINDF $=2.313$

$\mathrm{CFI}=.963$

TLI $=.941$

RMSEA $=.072$

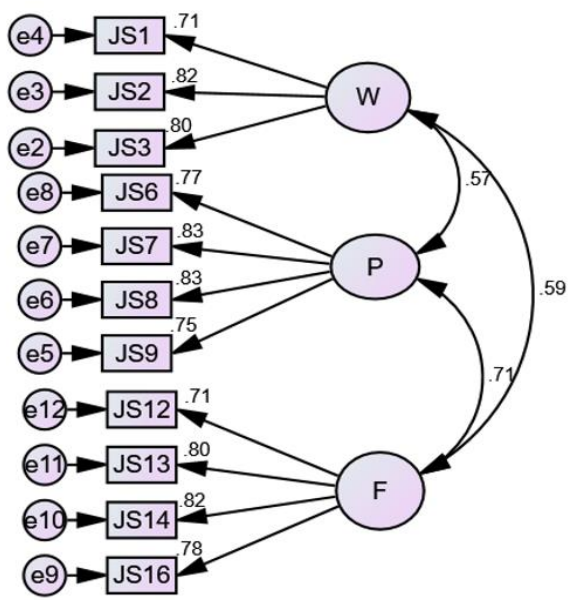


Similarly, the psychometric properties of the JS measurement model were determined through its convergent validity, discriminant validity, and composite reliability. As exhibited in Figure 3 above, the item loadings are considered acceptable as they were more than 0.50 (ranging from 0.71 to 0.83 ). Therefore, having item loadings above the threshold of 0.50 along with an average variance extracted of above 0.50 is satisfactory evidence of the model's convergent validity (Hair et al., 2014). Table 2 below also shows that the AVE values are more than the squared correlations for each set of constructs. According to Fornell and Larcker (1981), this is an acceptable evidence of discriminant validity. Finally, as shown in Table 3, the CR values are above 0.70 , which is good evidence of the model's reliability (Hair et al., 2014). The preceding results, therefore, fulfilled the first objective of the study.

Table 3

Convergent Validity, Discriminant Validity and Reliability of the JS Constructs

\begin{tabular}{lccccc}
\hline \multicolumn{1}{c}{ Sub Constructs } & $\mathbf{1}$ & $\mathbf{2}$ & $\mathbf{3}$ & AVE & CR \\
\hline Feedback & $\mathbf{0 . 6 0 6}$ & 0.346 & 0.499 & 0.606 & 0.860 \\
General Work & 0.589 & $\mathbf{0 . 6 0 6}$ & 0.326 & 0.606 & 0.821 \\
Promotion & 0.707 & 0.571 & $\mathbf{0 . 6 5 3}$ & 0.635 & 0.874 \\
\hline
\end{tabular}

Note. (i) Shown diagonally are the average variance extracted (AVEs) for each construct; below the diagonal is the correlation matrix; above the diagonal is the shared variance matrix; (ii) All AVEs were larger than the shared variances.

\section{Adequacy of the Hypothesized PDM-JS Structural Model}

To determine the validity of the measurement models for both PDM and JS via CFA, the study proceeded with the determination of the influence of PDM on administrative staff's JS from the hypothesized structural model (Figure 4). This analysis corresponds to the study's third hypothesis. According to the outcomes of the structural model, there is consistency between the hypothesized causal relationships and the data (relative Chi-square $=3.2$; RMSEA $=.061$; CFI $=.942 ; \mathrm{TLI}=.926$; Normed Chi-square $=1.976$ ), indicating that the entire fit indices had fulfilled their threshold values. Similarly, an examination of the hypothesized model shows that the parameter estimates were free from offending values with uncorrelated errors. The entire path coefficients of the causal structure were statistically significant at .01 level and were of practical importance. The standardized path coefficient of PDM $\rightarrow$ JS was substantial and statistically significant, $\beta=0.90$ (t-value $>1.96, p$-value $<0.001$ ). Thus, the second research objective was achieved, and Hypothesis 3 was supported. 


\section{Figure 4}

The Revised Full-fledged PDM- JS Structural Model

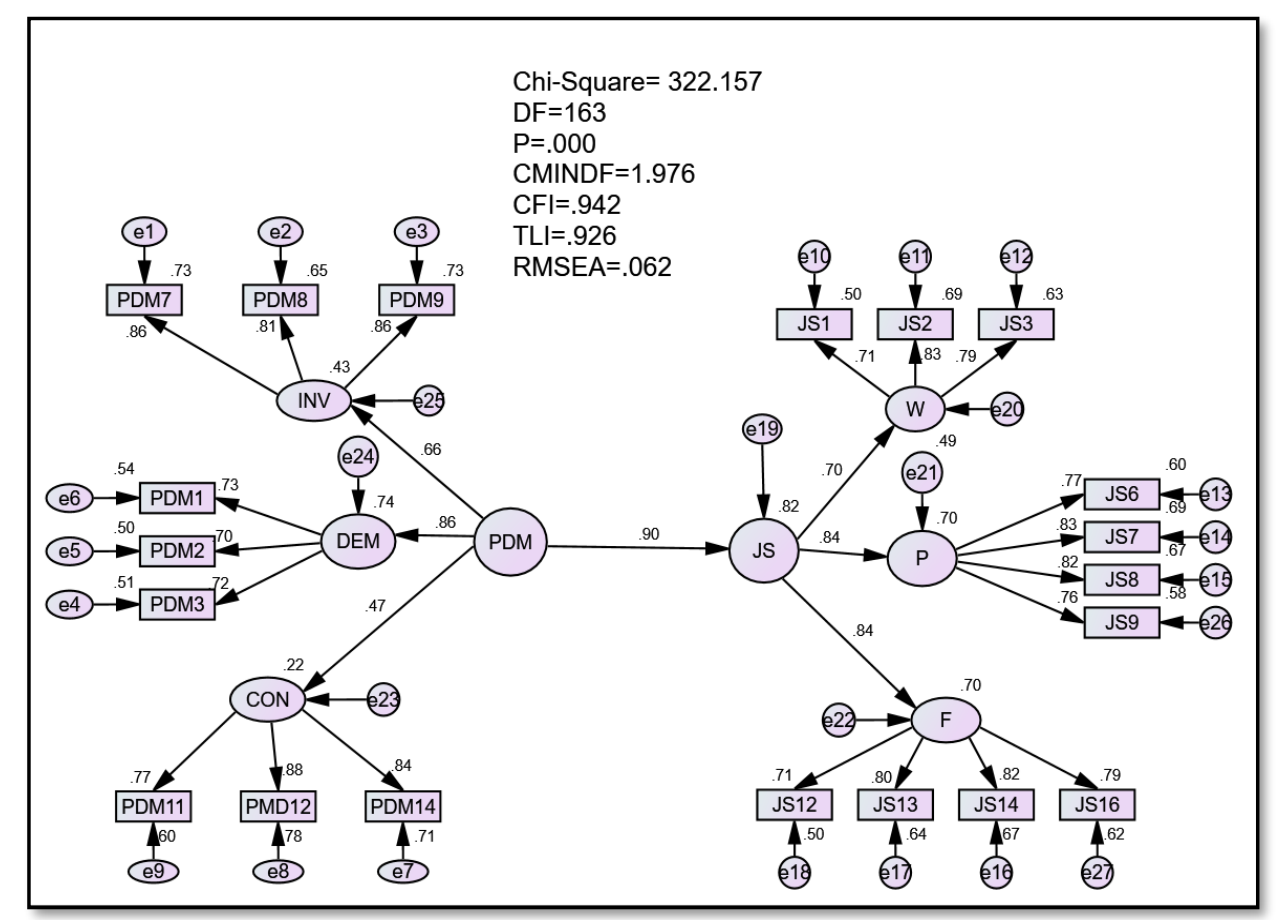

\section{Moderating Effect of Working Experience}

This section addresses the third research question and the fourth hypothesis (H4). Table 4 exhibits the results of the moderating effect of working experience on the influence of PDM on JS. The estimation of the constrained measurement model produced another Chi-square value, which was then tested against the baseline value for statistically significant differences (Kline, 2016; Byrne, 2013). The variance test for the structural model showed a statistically significant change in the Chi-square value across the five groups of staff's working experience (i.e., 1-3 years, 4-9 years, 10-14 years, 15-19 years and >19 years). That is, the increase in the Chi-square values from the unrestricted model to the constrained model produced a poorer model of the relationship between staff's PDM and JS.

The evidence, therefore, suggests that working experience moderated the relationship between staff's PDM and JS. This is because the path coefficient of those with either a very short or very long working experience was greater than that of those with moderate working experience. The path coefficients were 0.99 for staff who had between 1 and 3 years of working experience, 0.86 for those with 4 to 9 years, 0.69 for staff with 10 to 14 years, 0.75 for those with 15 to 19 years, and 0.86 for staff with over 19 years of experience in the administrative field. Thus, the influence of staff's PDM on their JS was greater among those with either a very short or very long duration of working experience, which led to the acceptance of the fourth hypothesis (H4). 


\section{Table 4}

Results of the Work Experience-Invariant Analysis

\begin{tabular}{llllll}
\hline Variable & \multicolumn{1}{c}{ Index } & Unconstrained & Constrained & Change & Decision \\
\hline Work & Chi-square & 1474.506 & 1481.021 & 6.515 & Groups are \\
Experience & Degree of freedom & 815 & 816 & 1 & different. \\
& & & & & \\
\hline
\end{tabular}

Table 5 summarizes the results of the hypothesis testing (H1 to H4). In essence, the results of this empirical study employing a covariance-based SEM found that both PDM and JS were valid and reliable multidimensional constructs, a finding that supported the hypothesized dimensions of the PDM and JS. Moreover, the results showed that administrative staff's PDM directly and significantly influenced their JS, while their working experience moderated the influence of PDM on JS.

Table 5

Summary of CFA and SEM Hypothesis Testing Results

\begin{tabular}{llr}
\hline & \multicolumn{1}{c}{ Hypothesis } & Results \\
\hline H1 & The multidimensional measure of PDM is valid and reliable. & Supported \\
H2 & The multidimensional measure of JS is valid and reliable. & Supported \\
H3 & $\begin{array}{l}\text { Administrative staff's PDM directly and significantly influences their } \\
\text { JS. }\end{array}$ & Supported \\
H4 & $\begin{array}{l}\text { Administrative staffs' working experience moderates the influence of } \\
\text { PDM on JS. }\end{array}$ & Supported \\
\hline
\end{tabular}

\section{DISCUSSION}

The study's first goal was to determine and confirm the three-factor model hypothesized for both PDM and JS. The results yielded evidence supporting the multidimensionality of PDM and JS, both of which comprised an underlying 3-factor model, thereby immensely expanding our understanding of the existence of the extracted subconstructs. The present study offers empirical evidence that PDM and JS are multidimensional concepts, as implicitly documented in earlier works (Hollyns, 2017; Muindi, 2011; Oloo \& Orwar, 2016). These three distinct but related dimensions of PDM and JS examined in the study can be described as follows: First, PDM comprised involved PDM, democratic PDM, and consultative PDM. Second, JS was comprised of elements that are related to general work, promotion, and feedback. Moreover, based on the results, the instrument measuring both PDM and JS used in the study was practically useful in diagnostic and evaluative assessments of administrative staff's job satisfaction as well as their work performance. 
The second goal was to understand how PDM influences JS. PDM was found to be linked to administrative staff's JS, with higher levels of decision-making engagement being consistently correlated with administrative staff's job satisfaction as hypothesized. Generally, this result supports the belief that PDM is an essential precondition to JS, while also establishing the importance of PDM in shaping JS. Summarily, the findings of the present study concur with previous research in this field (Mundi, 2011; Ugwu et al., 2019; Vente et al., 2016; Xia et al., 2016).

An important implication derived from the results is that researchers should avoid using and interpreting PDM as a unidimensional construct because it has been discovered to be a multidimensional concept. In fact, our results suggest the use of three separate scores - each on involved PDM, democratic PDM, and consultative PDM-as the indicators of the larger concept of PDM. Additionally, this study tested the moderating role of administrative staff's working experience in the relationship between their participation in decision making and job satisfaction. The multigroup analysis results showed that staff's working experience did moderate the effects of PDM on JS in varying degrees or levels. Although administrative staff's PDM had a significant impact on their JS for all experience groups' subsamples, the strengths of these impacts were not consistent across staff with different years of experience. In fact, those with less working experience showed increased JS when they were involved in PDM.

\section{IMPLICATIONS}

An important practical implication of the results is that the management of tertiary learning institutions should be more open and inclusive in their decision-making exercise and take advantage of staff participation as the important process involves their day-to-day work issues. This is to ensure that the tertiary institutions are able to tap the skills and knowledge of potential staff towards an effective management. PDM enhances the JS of administrative staff, which in turn improves their performance by making them feel motivated to work efficiently. It is also worth mentioning that previous studies have provided viewpoints on sharing information, motivation, and procedural justice to explain why workers are more satisfied when they are involved in the decision-making process. To explore the significance of the effects caused by PDM on JS, we set a different perspective of inquiry through this quantitative approach.

Nevertheless, the results also suggested that decision-making involvement is beneficial to workers and organizations because employees participating in decision-making are likely to experience high degrees of openness to be approached and are more likely to be happy with their jobs. Moreover, to maximize opportunities to engage in decision-making, leaders should set up project teams and decision panels. Also, they need to pay attention to engage with the work community by different possible means for ensuring their job satisfaction.

In terms of theoretical implications, this study produces new insights on the process of PDM, in regard to how it affects the JS of employees. This is significant because it means that involvement in decision-making creates more opportunities for employees to engage with 


\section{LIMITATIONS AND CONCLUSION}

Despite its merits, the current research is not without limitations, one of which concerns the sample, where the participants were confined to just one Islamic university in Malaysia, i.e., the International Islamic University Malaysia. Due to this sample restriction, it is not appropriate to generalize the research outcomes to the populations of all Islamic universities' administration staff. Moreover, this study had focused on a single predictor of administrative staff's job satisfaction and excluded other exogenous and mediating variables. Hence, future studies may consider the likelihood of other exogenous and mediating variables directly and indirectly affecting staff's job satisfaction. Variables like staff's loyalty and training can be considered for their mediating roles in the PDM-JS association.

Furthermore, this study was approached quantitatively with the constructs of PDM and JS being measured numerically. Hence, future studies could benefit from qualitative inquiry methods, such as interviews and anecdotes, or even from research designs that combine qualitative and quantitative techniques. Researchers should employ a combination of survey questionnaires and interviews to collect data to further investigate the information found in the study.

Finally, the influence of staffs' PDM on their JS in this study was considered significant and therefore, the implications are considered as being greatly important for the management of higher education institutions. However, the most critical question remains-Are the concerned higher educational institutions ready to adopt and adapt the study's findings for the betterment of their institutional management? This question should be taken up in further research attempting to understand the nature of PDM and JS and their likely association. managers and colleagues. Together, these possibilities and their psychological feelings improve their satisfaction with the job. Further, this study has established the moderating role of staff's experience on the association between PDM and JS. This is meaningful in relation to the communication that exists between employees and employers in higher education institutions. If appropriate communication takes place between them, it will positively influence their satisfaction and experience in all aspects of their work. 


\section{REFERENCES}

Abdulai I. A., \& Shafiwu A. B. (2014). Participatory decision making and employee productivity. A case study of community banks in the upper east region of Ghana. Business and Economics Journal. 5(3), 99.

AbuAlRub, R., El-Jardali, F., Jamal, D., \& Al-Rub, N. A. (2016). Exploring the relationship between work environment, job satisfaction, and intent to stay of Jordanian nurses in underserved areas. Applied Nursing Research, 31, 19-23.

Armstrong, M. (2006). A Handbook of Human Resource Management Practice (10 ${ }^{\text {th }}$ edn.) Kogan page.

Badrianto, Y., \& Ekhsan, M. (2020). Effect of work environment and job satisfaction on employee performance in pt. Nesinak industries. Journal of Business, Management, \& Accounting, 2(1).

Balakrishnan, V., (1997). Participation in Decision Making in the Public Service Department. [Masters of Education dissertation]. International Islamic University Malaysia.

Bavendum, J. (2000). Managing Job Satisfaction, New York: New York Research Inc.Bayram, H. \& Dinç, S. (2015). Role of transformational leadership on employee's job satisfaction: the case of private universities in Bosnia and Herzegovina. European Researcher, 93, 4, 270-281.

Beardwell, J. \& Claydon, J. (2007). Human Resource Management: A Contemporary Approach (5th edn.). Pearson Education.

Bhatti, K. and Nawab, S. (2011). Effect of Direct Participation on Organizational Commitment. International Journal of Business and Social Science, 2 (9).

Bilge, G., Hehl-Lange, S. \& Lange, E. (2016). The use of mobile devices in participatory decision-making. Journal of Digital Landscape Architecture, 1, 234-242.

Busck, O, Knudsen, H. and Lind, J. (2010). The Transformation of Employee Participation: Consequences for the Work Environment. Economic and Industrial Democracy, 31(3), 285-305.

Chandra, T. (2016). The Influence of Leadership Styles, Work Environment and Job Satisfaction of Employee Performance: Studies in the School of SMPN 10 Surabaya. International Education Studies, 9(1), 131-140.

Devente, J., Reed, M. S., Stringer, L. C., Valente, S. \& Newig, J. (2016). How does the context and design of participatory decision making processes affect their outcomes? Evidence from sustainable land management in global drylands. Ecology and Society, 21 (2), 24. http://dx.doi.org/10.5751/ES-08053-210224

Emmanuel, I. C. \& Damachi J.U. (2015). Employees' participation in decision making and the hospitality industry in Nigeria: an investigative study of selected hotels in the Federal Capital Territory, Abuja, Nigeria. Academic Journal of Economic Studies, 1(4), 54-66. 
Farinde-Wu, A. \& Fitchett, P.G. (2016). Searching for Satisfaction: Black Female Teachers' Workplace Climate and Job Satisfaction. Urban Education, 53(1), 86-112. https://doi.org/10.1177/0042085916648745

Fassoulis, K \& Alexopoulos, N. (2015), The workplace as a factor of job satisfaction and productivity: a case study of administrative personnel at the University of Athens. Journal of Facilities Management, 13, 4. http://dx.doi.org/10.1108/JFM-06 2014-0018

Fornell, C. \& Larcker, D.F. 1(981). Evaluating structural equation models with unobservable variables and measurement error. Journal of Marketing Research, 18 (1), 39-50. Graham, H. T. \& Bennett, R. (1998). Human Resources Management, 9th Ed. 4edge Ltd, Hockley.

Gumato, U. (2003). Survey of the Relationship between the Perceived Empowerment and Job Satisfaction of Employees in Commercial Banks in Nairobi,' [Published MBA Master Thesis]. University of Nairobi.

Guion, R. (1958). Industrial morale (a symposium) - the problems of terminology, Personnel Psychology, 11, 59-64.

Hair, J., Black, B., Babin, B., Anderson, R. \& Tatham, R. (2006). Multivariate Data Analysis (6th edition). Prentice-Hall.

Hayes, B., Douglas, C., \& Bonner, A. (2015). Work environment, job satisfaction, stress and burnout among haemodialysis nurses. Journal of nursing management, 23(5), 588598.

Hertzberg, F., Mausner, B. \& Snyderman, B. (1957). The Motivation of Work. Wiley.

Hulin, C. L. (1976). Job satisfaction and turnover in a female clerical population. In M. M. Gruneberg (Ed.), Job satisfaction-a reader (pp. 218-228). John Wiley \& Sons.

Kennan, D., Brady, B. \& Forkan, C. (2018). Supporting children's participation in decision making: a systematic literature review exploring the effectiveness of participatory processes. British Journal of Social Work, 48(7), 1982-2002.

Asad Khan, M. A., Md Yusoff, R., Hussain, A. \& Binti Ismail, F. (2018). The mediating effect of job satisfaction on the relationship of HR practices and employee job performance: empirical evidence from higher education sector. International Journal of Organizational Leadership, 8(1), 78-94.

Könings, K. D., Bovill, C. \& Woolner, P. (2017). Towards an interdisciplinary model of practice for participatory building design in education. European Journal of Education, 52(3), 306-317.

Kuye O. L. \& Sulaimon A. A. (2011). Employee involvement in decision making and firm performance in the manufacturing sector in Nigeria. Serbian Journal of Management, $6(1), 1-15$.

Lawler I. E. (1971). New Approach in Pay Innovation that Works in J-Gordon, Pay and Organizational Effectiveness: A Psychological View. McGraw-Hill. 
Locke, E. A. (1969). What is job satisfaction? Organizational Behavior and Human Performance, 4, 309-336.

Luthans, F. (2005). Organizational Behavior (10th edn.). McGraw-Hill Irwin.

Mira, M. S., Choong, Y. V. \& Thim, C. K. (2019). The effect of HRM practices and employees' job satisfaction on employee performance. Management Science Letters, 9(6), 771-786.

Monge P. R., \& Miller K. I. (1988). Participative processes in organizations. Handbook of Organizational Communication, 21329, 68.

Moorhead, G. \& Griffin, R. (2004). Organizational Behavior: Managing People and Organizations. (7th edn..) Houghton Mifflin Company.

Muindi, F.K. (2011). The relationship between participation in decision making and job satisfaction among academic staff in the school of business, University of Nairobi. Journal of Human Resource Management Research.

Mwaura, S. M. (1993). Probable causes of Job Dissatisfaction among the University of Nairobi Library Workers. [Published MBA Project]. University of Nairobi

Oloo, P.A. \& Orwar, B.H. (2016). Influence of Participatory Decision Making of Junior Staff at the Retail Markets in Kenya: An Empirical Study of Uchumi Supermarket in Nairobi. International Journal of Education and Research, 4, 2.

Noah, Y. (2008). A Study of Worker Participation in Management Decision Making Within Selected Establishments in Lagos. Nigeria Journal of Social Science, 17 (1), 31-39.

Pang, K. \& Lu, C. (2018). Organizational motivation, employee job satisfaction and organizational performance: An empirical study of container shipping companies in Taiwan. Maritime Business Review, 3(1), 36-52.

Chizoba, P., Abomeh, O., Chika, M., \& MbaNjide, M. (2019). Impact of Participatory Decision Making on Organisational Goal Attainment. International journal of business and economics, 6, 1-15.

Probst, T. M. (2005). Considering the Negative Effects of Job Insecurity through Participative Decision Making: Lessons from the Demand- Control Model. Journal of Occupational Health Psychology, 10, 320-329.

Seidou, P. (1999). IIUM Lecturers' Participation in Academic Administrative and University Policy Decision-making. [Unpublished Master Thesis]. International Islamic University Malaysia.

Spector, P. E. (1997). Job Satisfaction: Application, Assessment, Causes, and Consequences. SAGE.

Ugwu, K.E., Okrocji, L.I. \& Chukwu, E.O. (2019). Participative decision making and employee performance in the hospitality industry: a study of selected hotels in Owerri Metropolis, Imo State. Management Studies and Economic Systems (MSES), 4(1), 5770 . 
Vente, J. D., Reed, M. S., Stringer, L. C., Valente, S. \& Newig, J. (2016). How does the context and design of participatory decision making processes affect their outcomes? Evidence from sustainable land management in global drylands. Ecology and Society, 21(2), 24. http://dx.doi.org/10.5751/ES-08053-210224

Wagner, A. J. (1994). Participation's effects on performance and satisfaction: a reconsideration of research evidence. Academy of Management Review, 19, 312-30.

Wang, T. K., \& Brower, R. (2019). Job satisfaction among federal employees: The role of employee interaction with work environment. Public Personnel Management, 48(1), 3-26.

Westhuizen, D. (2010). Culture, Participative Decision Making and Job Satisfaction. Economic and Industrial Democracy, 31(3), 285-305.

Wilcock, A. \& Wright, M. (1991). Quality of work life in the knitwear sector of the Canadian textile industry. Public Personnel Management, 20, 19.

Xia, Y., Zhang, L. \& Zhao, N. (2016). Impact of participation in decision making on Job satisfaction: an organizational communication perspective. Spanish Journal of Psychology, 19, 1-14. 